prescribed mianserin hydrochloride in doses varying from $30 \mathrm{mg}$ to $60 \mathrm{mg}$ per day, depending on the side effects. In the 12 months since commencing mianserin the patient has had no depressive episodes.

This patient's illness was obviously atypical in appearing at such an early age. However, it was typical in that it responded to treatment with adequate doses of lithium. Since, in the previous year, simply the reduction in dosage of lithium had led to the reappearance of the illness and, from a reliable history, the attacks had been occurring frequently over 8 years, it seems unlikely that the absence of depression when on mianserin was purely due to chance.

That mianserin may prevent recurrent depression is important, since our present therapeutic armamentarium for prophylaxis is very limited. Though we have at our disposal a large number of antidepressant drugs, most of them are pharmacologically very similar and in effect we have only a small number of distinct antidepressant treatments (EGT, tricyclic drugs, monoamine oxidase inhibitors with or without tryptophan). It is therefore of considerable importance that a new antidepressant may be effective when tricyclic drugs have failed.

\section{G. J. NAYLOR}

Department of Psychiatry,

Ninewells Hospital and Medical School, Dundee $D D_{2}{ }_{1} U B$

\section{References}

Murphy, J. E. (1975) Journal of International Medical Research, 3, $25^{\mathrm{I}-60}$.

Coppen, A., Gupta, R., Montgomery, S., Ghose, K., Bailey, J., Burns, B. \& De Ridder, J. J. (1976) British Journal of Psychiatry, 129, 342-5.

\section{DIAGNOSIS OF PSYGHIATRIG ILLNESS}

DeAr Sir,

While it may be true that the absence of laboratory investigations 'forces the psychiatrist to base his diagnosis firmly on the clinical interview' at De Crespigny Park (as indicated by Dr Leff, Fournal (1977), 131, 329-38), I do not think this is the case in everyday busy clinical practice, even in Aarhus, Agra, Cali, or Ibadan.

What most of us really do, is to try to get a history from an informant, or observe the subsequent course of the illness, or response to treatment.

An excited gentleman presenting himself at the emergency room at 2 in the morning, smelling of alcohol, and saying that he is the Emperor of China, might be one of many things. He could be manic, or schizophrenic, an acidhead, a speed freak, a drunk with a distorted sense of humour, a sociologist with a distorted sense of mission, or a descendant of the Manchus who lost his way to the men's room. My interview with such a patient would tell me little of much use at 2 in the morning, whereas five minutes with his family would give me the diagnosis, especially if they knew his previous response to lithium, sobriety, or phenothiazines.

\section{North Airmond Road, Suffern, New York rogor}

\section{DeAr Sir,}

I am grateful to Dr Birkett for drawing attention to an apparent omission from my review. I certainly did not mean to exclude the psychiatric history in using the term 'clinical interview'. The reason my review deals exclusively with examination of the mental state is that published work on international comparisons of the influence of the psychiatric history on diagnostic practice is extremely sparse. However, there are some indications in the International Pilot Study of Schizophrenia that the psychiatric history plays a much greater part in shaping diagnosis in some countries than in others. The emphasis placed by Moscow psychiatrists on the course of illness and the patients' social adjustment allows us to infer that they would be extremely reluctant to make a differential diagnosis between schizophrenia and an affective psychosis without this information. Their colleagues in Aarhus, Agra, Gali or Ibadan, by contrast, would be much more likely to make such a diagnostic distinction on the basis of the mental state alone.

The other point raised by Dr Birkett is the lack of time available for examining the mental state in a busy clinic in whatever part of the world it happens to be. It is true, as mentioned in my review, that diagnostic decisions are made early on in the clinical interview, but there is considerable latitude, even within three minutes, for great differences in emphasis on phenomenology. Let us consider his point about the response to lithium indicating a diagnosis of mania. It is evident from both the IPSS and the US : UK project that up to a short time ago mania was virtually never demarcated from schizophrenia by American psychiatrists. Their rediscovery of the prophylactic effectiveness of lithium in mania has led to an increasing recognition by Americans of the existence of this condition. British psychiatrists, however, have been consistently making a distinction between mania and schizophrenia for many decades 